\title{
G (- \\ Fluorescence labeling of a NaV1.7-targeted peptide for near-infrared nerve visualization
}

Junior Gonzales

Memorial Sloan Kettering Cancer Center

Giacomo Pirovano

Memorial Sloan Kettering Cancer Center https://orcid.org/0000-0001-8862-3613

Chun Yuen Chow

University of Queensland

Paula Demetrio de Souza Franca

Memorial Sloan Kettering Cancer Center

Lukas M. Carter

Memorial Sloan Kettering Cancer Center

Julie Kaae Klint

University of Queensland

Navjot Guru

Memorial Sloan Kettering Cancer Center

Jason S. Lewis

Memorial Sloan Kettering Cancer Center

Glenn F. King

University of Queensland

Thomas Reiner ( $\nabla$ reinert@mskcc.org )

https://orcid.org/0000-0002-7819-5480

Original research

Keywords: Hs1a-FL, nerve imaging, near-infrared imaging, intraoperative

Posted Date: February 25th, 2020

DOI: https://doi.org/10.21203/rs.2.24381/v1

License: (1) This work is licensed under a Creative Commons Attribution 4.0 International License.

Read Full License 


\section{Abstract}

Purpose Accidental peripheral nerve injury during surgical intervention results in a broad spectrum of potentially debilitating side effects. Tissue distortion and poor visibility can significantly increase the risk of nerve injury with long-lasting consequences for the patient. We developed and characterized Hs1a-FL, a fluorescent near-infrared molecule for nerve visualization in the operating theater with the aim of helping physicians to visualize nerves during surgery.

Methods Hs1a was derived from the venom of the Chinese bird spider, Haplopelma schmidti, and conjugated to Cy7.5 dye. Hs1a-FL was injected intravenously in mice and harvested nerves were imaged microscopically and with epifluorescence.

Results Hs1a-FL showed specific and stable binding to the sodium channel Na v 1.7, present on the surface of human and mouse nerves. Hs1a-FL allowed epifluorescence visualization of sciatic mouse nerves with favorable nerve-to-muscle contrast.

Conclusions Fluorescent Na v 1.7-targeted tracers have the potential to be adopted clinically for the intraoperative visualization of peripheral nerves during surgery, providing guidance for the surgeon and potentially improving the standard of care.

\section{Introduction}

Unintentional resection or injury of nerves during medical interventions is a significant concern during surgery $[1,2]$. During surgery, there is always a degree of risk for nerves to be cut, crushed, tied off, penetrated and twisted by screws, or even injured during the removal of devices. In addition, they can be stretched by retractors, cut, or thermally damaged by electric knife, hardening bone cement or during coagulation [3,4]. These unintentional, iatrogenic complications typically occur because nerves are not clearly visible to the surgeon or could be mistaken for a vessel or tendon. Certain surgical procedures are considered high risk for resulting in nerve injury. These include, but are not limited to, osteosynthesis and osteotomy, arthrodesis, lymph node biopsy in the neck, parotidectomies, thyroid surgeries, carpal tunnel syndrome surgery, varicose vein surgery, excision of Baker cysts, and inguinal herniorrhaphies.

For example, in head and neck surgery, iatrogenic nerve injuries can result in facial paralysis, hoarseness or weakening of voice, respiratory distress and other neurological complications with harsh lifestyle implications for the patient [5-8]. As a result, one out of four patients with neuropathic pain identify surgical morbidity as the originating cause [9]. Oncologic surgery, in particular, poses a risk of nerve injury as anatomy is often distorted by the disease [10-17]. Tools for pre and perioperative nerve enhancement exist [18-20] and fluorescent nerve imaging agents, as well as multimodal optical imaging techniques, are raising interest for intraoperative applications [21-31]. However, the availability of an intraoperative imaging agent that could clearly identify small nerve branches or even larger trunks below the tissue surface, especially in cases of reoperation when normal anatomy is disrupted, could significantly improve 
surgical precision. In an attempt to respond to this need, we developed Hs1a-FL, a near-infrared imaging agent that could be used in the described surgical settings.

Recombinant peptide Hs1a was derived from the venom of the Chinese bird spider, Haplopelma schmidti. Hs1a proved to be a potent and subtype-selective inhibitor of sodium channel $\mathrm{Na}_{\mathrm{v}} 1.7$, a key signaltransmitter located on nerve surfaces [32]. Our fluorescently labeled version of $\mathrm{Hs} 1 \mathrm{a}$ targets $\mathrm{Na}_{\mathrm{V}} 1.7$ receptors and has the potential to be used as a vector for delivering an optical sensor to peripheral nerves in vivo. We show that the labeling of Hs1a with Cy7.5 N-hydroxy succinimide (NHS) ester could be used as a practical tool for nerve visualization during surgery in a preclinical mouse model (Fig. 1a). We anticipate that this technology will have the potential to directly impact the surgical standard of care by lending contrast to nerves, thereby decreasing iatrogenic injury and therefore surgical morbidity.

\section{Material And Methods}

\section{General}

Unless otherwise stated, all solvents and reagents were obtained from Sigma-Aldrich or Fisher Scientific and were used without further purification. Cyanine7.5 (Cy7.5) was purchased from Lumiprobe (Maryland, USA). Anti-Na 1.7 antibody [N68/6] was purchased from Abcam (ab85015). Water (>18.2 $\mathrm{M} \Omega \bullet \mathrm{cm}$ at $25^{\circ} \mathrm{C}$ ) was obtained from an Alpha-Q Ultrapure water system (Millipore). Acetonitrile (AcN) was of high-performance liquid chromatography (HPLC) grade and was purchased from Fisher Scientific. Phosphate-buffered saline (PBS) without $\mathrm{Ca}^{2+}$ or $\mathrm{Mg}^{2+}$ was obtained from the Media Preparation Facility at Memorial Sloan Kettering Cancer Center (MSKCC) and used for all in vivo injections. Reverse-phase (RP) HPLC purifications were performed on a Shimadzu HPLC system equipped with a DGU-20A degasser, SPD-M20A UV detector, LC-20AB pump system, and a CBM-20A communication bus module using RP-HPLC columns (Atlantis T3 C18, $5 \mu \mathrm{m}, 4.6 \times 250$ mm, P/N: 186003748). Epifluorescence imaging was performed on an IVIS Spectrum imaging system (PerkinElmer). Confocal microscopy images were captured using a Leica SP8 inverted-stand confocal microscope equipped a tunable white light laser that ranges from 470 to $670 \mathrm{~nm}$. The microscope is also equipped with a $405 \mathrm{~nm}$ diode, argon laser (with $476 \mathrm{~nm}, 488 \mathrm{~nm}, 496 \mathrm{~nm}$ and $514 \mathrm{~nm}$ laser line) and a $725 \mathrm{~nm}$ laser for near infra-red NIR imaging coupled with avalanche photo diode detectors (APDs) which were used for detection of Hs1a-FL.

\section{Synthesis of Hs1a}

Recombinant Hs1a was produced via expression in the periplasm of $E$. coli using a protocol optimized for production of disulfide-rich peptides [33]. The recombinant peptide containing a non-native N-terminal glycine residue was purified by nickel affinity chromatography after liberation from the $\mathrm{His}_{6}-\mathrm{MBP}$ fusion tag via cleavage with tobacco etch virus protease. LC-ESI-MS (ES+), $\mathrm{m} / \mathrm{z}$ calculated for $\left[\mathrm{C}_{164} \mathrm{H}_{251} \mathrm{~N}_{49} \mathrm{O}_{47} \mathrm{~S}_{6}\right] 3850.74,\left[\mathrm{C}_{164} \mathrm{H}_{251} \mathrm{~N}_{49} \mathrm{O}_{47} \mathrm{~S}_{6}+3 \mathrm{H}\right]^{3+} 1284.58$, found $[\mathrm{M}+3 \mathrm{H}]^{3+} 1285.00$, 
$\left[\mathrm{C}_{164} \mathrm{H}_{251} \mathrm{~N}_{49} \mathrm{O}_{47} \mathrm{~S}_{6}+4 \mathrm{H}\right]^{4+} 963.69$, found $[\mathrm{M}+4 \mathrm{H}]^{4+} 964.20,\left[\mathrm{C}_{164} \mathrm{H}_{251} \mathrm{~N}_{49} \mathrm{O}_{47} \mathrm{~S}_{6}+5 \mathrm{H}\right]^{5+} 771.15$, found $[\mathrm{M}+5 \mathrm{H}]^{5+} 772.60,\left[\mathrm{C}_{164} \mathrm{H}_{251} \mathrm{~N}_{49} \mathrm{O}_{47} \mathrm{~S}_{6}+6 \mathrm{H}\right]^{6+} 642.79$, found 643.25 .

\section{Synthesis of Hs1a-FL}

Recombinant Hs1a peptide $(0.26 \mathrm{mM}, 200 \mu \mathrm{g}$ in $200 \mu \mathrm{L}$ of $\mathrm{AcN})$ and $\mathrm{Na}_{2} \mathrm{CO}_{3}(1 \mathrm{M}, 40 \mu \mathrm{L})$ were transferred into a $3 \mathrm{~mL}$ amber vial with a magnetic bar stirrer. Cy7.5-NHS ( $4 \mu \mathrm{L}$ of a $24 \mathrm{mM}$ solution) was dissolved in $\mathrm{AcN}$ and added dropwise to the reaction mixture. The final volume of the reaction mixture was $350 \mu \mathrm{L}$. The reaction mixture was stirred for at least 10 min before dilution with $100 \mu \mathrm{L}$ of water. This reaction produced mono- and di- adducts of Cy7.5, which were purified and separated using RP-HPLC. Fractions containing the mono-adduct of Hs1a-FL were concentrated, then the solvent was removed in vacuo to afford a dark greenish powder ( $20 \mu \mathrm{g}, 14 \%$ yield from Hs1a peptide). This purified compound was then formulated in $100 \% \mathrm{Ca}^{2+} / \mathrm{Mg}^{2+}$-free PBS or $10 \%$ dimethyl sulfoxide (DMSO) and PBS. LC-ESI-MS (ES+), $\mathrm{m} / \mathrm{z}$ calculated for $\left[\mathrm{C}_{209} \mathrm{H}_{298} \mathrm{~N}_{51} \mathrm{O}_{48} \mathrm{~S}_{6}\right]$ 4482.12, $\left[\mathrm{C}_{209} \mathrm{H}_{298} \mathrm{~N}_{51} \mathrm{O}_{48} \mathrm{~S}_{6}+3 \mathrm{H}\right]^{3+} 1495.04$, found $[\mathrm{M}+3 \mathrm{H}]^{3+}$ 1495.45, $\left[\mathrm{C}_{209} \mathrm{H}_{298} \mathrm{~N}_{51} \mathrm{O}_{48} \mathrm{~S}_{6}+4 \mathrm{H}\right]^{4+} 1121.53$, found $[\mathrm{M}+4 \mathrm{H}]^{4+} 1121.75,\left[\mathrm{C}_{209} \mathrm{H}_{298} \mathrm{~N}_{51} \mathrm{O}_{48} \mathrm{~S}_{6}+5 \mathrm{H}\right]^{5+} 897.42$, found $[\mathrm{M}+5 \mathrm{H}]^{5+} 897.75,\left[\mathrm{C}_{209} \mathrm{H}_{298} \mathrm{~N}_{51} \mathrm{O}_{48} \mathrm{~S}_{6}+6 \mathrm{H}\right]^{6+} 748.02$, found $[\mathrm{M}+6 \mathrm{H}]^{6+} 748.25$

\section{Cell Lines}

HEK293 cells stably expressing the human $\mathrm{Na}_{\mathrm{V}}$ channel b1 subunit ( $\mathrm{hNa} \mathrm{V}_{\mathrm{V}} \mathrm{b}$ ) in combination with the a

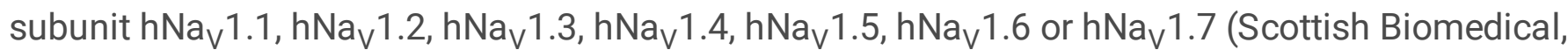
Glasgow, UK) were cultured in DMEM/F-12 media (1:1), supplemented with $10 \%$ fetal bovine serum, 400 $\mathrm{mg} / \mathrm{mL}$ geneticin and $100 \mathrm{mM}$ non-essential amino acids (all reagents from Invitrogen) at $37^{\circ} \mathrm{C}$ and in $5 \%$ $\mathrm{CO}_{2}$.

\section{Electrophysiology}

Whole-cell patch-clamp experiments were performed at room temperature using a QPatch 16x automated electrophysiology platform (Sophion Bioscience, Denmark) using 16-channel planar patch-chip plates (QPlates) with a patch-hole diameter of $1 \mu \mathrm{m}$ and resistance of $2 \mathrm{M} \Omega$. Whole-cell currents were filtered at $5 \mathrm{kHz}$ (8-pole Bessel) and digitized at $25 \mathrm{kHz}$. A P4 online leak-subtraction protocol was used with nonleak-subtracted currents acquired in parallel. The extracellular solution was $2 \mathrm{mM} \mathrm{CaCl}, 1 \mathrm{mM} \mathrm{MgCl}, 10$ $\mathrm{mM}$ HEPES, $4 \mathrm{mM} \mathrm{KCl}, 145 \mathrm{mM} \mathrm{NaCl}$ at pH 7.4 and the intracellular solution was $140 \mathrm{mM} \mathrm{CsF}, 1 \mathrm{mM} / 5$ $\mathrm{mM}$ EGTA/CsOH, $10 \mathrm{mM}$ HEPES, $10 \mathrm{mM} \mathrm{NaCl}$ at pH 7.3. Hs1a-FL were dissolved in extracellular solution with $0.1 \%$ bovine serum albumin (BSA). Concentration-response data were obtained using five 
concentrations of peptide ( $2 \mathrm{nM}$ to $10 \mu \mathrm{M})$. HEK293-hNa cells were clamped at a holding potential of $60 \mathrm{mV}$ for $\mathrm{Na}_{\mathrm{v}} 1.1,-65 \mathrm{mV}$ for $\mathrm{Na}_{\mathrm{v}} 1.2,-60 \mathrm{mV}$ for $\mathrm{Na}_{\mathrm{v}} 1.3,-75 \mathrm{mV}$ for $\mathrm{Na}_{\mathrm{v}} 1.4,-105 \mathrm{mV}$ for $\mathrm{Na}_{\mathrm{v}} 1.5,-60$ $\mathrm{mV}$ for $\mathrm{Na}_{\mathrm{V}} 1.6$ and $-75 \mathrm{mV}$ for $\mathrm{Na}_{\mathrm{V}}$ 1.7. For each concentration, $10 \mu \mathrm{L}$ of peptide was added for $6 \mathrm{~s}$ before applying the following voltage protocol: $-80 \mathrm{mV}$ for $10 \mathrm{~ms},-120 \mathrm{mV}$ for $200 \mathrm{~ms}, 0 \mathrm{mV}$ for $20 \mathrm{~ms}$, then return to $-80 \mathrm{mV}$ potential. This was repeated once every $60 \mathrm{~s}$ during liquid applications. Cells were otherwise held at the holding potential when the above voltage protocol was not executed. Upon establishment of the whole cell recording configuration, a total of five applications of the extracellular solution ( $1 \mathrm{x}$ control buffer, $3 \mathrm{x}$ test compound/control, $1 \mu \mathrm{M}$ tetrodotoxin (TTX; positive control)), all containing $0.1 \%$ BSA (except for the TTX solution) were made on each cell. The voltage protocol was executed 10 times after each application. Currents were sampled at $25 \mathrm{kHz}$ and filtered at $5 \mathrm{kHz}$ with an 8-pole Bessel filter. The series resistance compensation level was set at $80 \%$. All experiments were performed at room temperature $\left(\sim 22^{\circ} \mathrm{C}\right)$. $\mathrm{IC}_{50}$ values were determined from non-linear regression of concentration-response data using GraphPad Prism.

\section{Animal Studies}

Female athymic nude mice (4-8 weeks old, athymic-Nude (outbred) (Stock\#:088; Envigo, USA) were allowed to acclimatize at the MSKCC vivarium for 1 week with ad libitum food and water prior to the experimental procedure. For imaging experiments, animals were sacrificed 30 min post-tail vein injection of Hs1a-FL, Hs1a/Hs1a-FL or PBS. All animal experiments were performed in accordance with institutional guidelines and approved by the MSKCC Institutional Animal Care and Use Committee, following NIH guidelines for animal welfare.

\section{Mouse Cryosectioning and Image-based Reconstruction}

Post-euthanasia, a representative mouse was fast frozen in hexanes with dry ice. Coronal cryosectioning and white-light imaging were performed by EMIT using a Xerra imager; following each sequential removal of $50 \mu \mathrm{m}$ thick slices, the tissue-embedded block was imaged at $30 \mu \mathrm{m}$ in-plane resolution. A 3D image volume of the mouse was generated through multiplanar reformation using 3D Slicer software for anatomic visualization (Fig. 1a).

\section{Immunohistochemistry}

Immunohistochemical (IHC) staining experiments were used to detect the expression and abundance of sodium channel $\mathrm{Na}_{\mathrm{V}} 1.7$ in mouse sciatic nerve tissue. Anti-Na 1.7 antibody [N68/6] (Abcam ab85015) was found to specifically bind to mouse $\mathrm{Na}_{\mathrm{v}} 1.7(0.5 \mu \mathrm{g} / \mathrm{mL})$. Paraffin-embedded formalin-fixed $5 \mu \mathrm{m}$ 
sections were deparaffinized with EZPrep buffer. For IHC detection, a 3,3'-diaminobenzidine (DAB) detection kit (Ventana Medical Systems, Tucson, AZ) was used according to the manufacturer's instructions. These experiments were performed at the MSKCC Molecular Cytology Core Facility using the Discovery XT processor (Ventana Medical System, Tucson, AZ). Adjacent sections were stained against IgG, to control for non-specific binding to $\mathrm{Na}_{\mathrm{V}}$ 1.7. Sections were counterstained with hematoxylin and eosin (H\&E) and coverslipped with Permount (Fisher Scientific, Pittsburgh, PA) for morphological evaluation of tissue characteristics.

\section{Confocal Microscopy}

For the confocal microscopy experiments, $5 \mu \mathrm{m}$ cryosections of sciatic nerve tissues embedded in optimal cutting temperature compound (OCT) were used to determine the distribution and localization of $\mathrm{Hs} 1 \mathrm{a}-\mathrm{FL}$ from mice previously injected with the fluorescent agent Hs1a-FL (4 nmol, $45 \mu \mathrm{M}$ of Hs1a-FL in $100 \mu \mathrm{L}$ of PBS), the blocking solution Hs1a/Hs1a-FL (Hs1a-FL, $45 \mu \mathrm{M}, 4 \mathrm{nmol}$ and Hs1a $120 \mu \mathrm{M}, 12 \mathrm{nmol}$ in $100 \mu \mathrm{L}$ PBS), or $100 \mu \mathrm{L}$ of PBS. These resected nerves were incubated with Hoechst $33342(20 \mu \mathrm{M}, 1$ $\mathrm{nmol}$ in $50 \mu \mathrm{L}$ of PBS) to counterstain nuclei, which were subsequently embedded in Mowiol mounting medium. Fresh tissues were counterstained with Hoechst $33342(20 \mu \mathrm{M}, 1 \mathrm{nmol}$ in $50 \mu \mathrm{L}$ of PBS) and samples placed directly on a microscope slide for detection of the fluorescence signal of the fluorescent peptide.

\section{Epifluorescence Imaging}

One group of animals was intravenously injected with Hs1a-FL (4 nmol, $45 \mu \mathrm{M}$ of Hs1a-FL in $100 \mu \mathrm{L}$ of PBS, $n=3$ ). A second group of animals was injected with Hs1a and Hs1a-FL (Hs1a-FL, $45 \mu \mathrm{M}, 4 \mathrm{nmol}$ and $\mathrm{Hs} 1 \mathrm{a}, 120 \mu \mathrm{M}, 12 \mathrm{nmol}$ in $100 \mu \mathrm{L}$ PBS, $\mathrm{n}=3)$ or PBS $(\mathrm{n}=3)$. Animals were sacrificed 30 min postinjection and epifluorescence images obtained. Epifluorescence images of the right sciatic nerve (RSN) and left sciatic nerve (LSN) were obtained in situ from all the mice in the study. Epifluorescence images of the biodistribution included RSN, LSN, muscle, heart, kidney, liver and brain, and were acquired with an IVIS Spectrum imaging system (PerkinElmer) using a predetermined filter set (excitation $=710 / 45 \mathrm{~nm}$, emission $=800-820 \mathrm{~nm}$ ). Autofluorescence was removed through spectral unmixing. Semiquantitative analysis of the Hs1a-FL signal was conducted by measuring the average radiant efficiency (in units of $\left[\mathrm{p} / \mathrm{s} / \mathrm{cm}^{2} / \mathrm{sr}\right] /\left[\mu \mathrm{W} / \mathrm{cm}^{2}\right]$ ) in regions of interest (ROIs) that were placed on all resected nerves and as well in all organs from the biodistribution under white light guidance.

\section{Statistical Analyses}


Statistical analyses were performed using GraphPad Prism 8. Unless otherwise stated, data points represent mean values, and error bars represent standard deviations of biological replicates. All $p$-values were calculated using an unpaired $t$-test. Statistical significance was considered for $p$-values $<0.05$ and as follows: $n s=$ not significant, ${ }^{*} p<0.05,{ }^{\star *} p<0.01,{ }^{\star \star *} p<0.001$.

\section{Results}

\section{Selectivity of Hs1a across lon Channel Subtypes}

Hs1a peptide was isolated from venom of the Chinese tarantula Haplopelma schmidti. To assess the selectivity across the various $\mathrm{Na}_{\mathrm{v}}$ channel subtypes, $\mathrm{Hs} 1$ a was tested on human $\mathrm{Na}_{\mathrm{v}} 1.1-\mathrm{Na}_{\mathrm{v}} 1.7$ channels stably expressed in HEK293 cells using automated patch-clamp techniques. Hs1a was shown to have inhibitory affinity for neuronal $\mathrm{Na}_{\mathrm{v}}$ channels, with $\mathrm{IC}_{50}$ values in the low nanomolar range (19.4, 82, 107, 19.2, $26.9 \mathrm{nM}$ for $\mathrm{Na}_{v} 1.1, \mathrm{Na}_{v} 1.2, \mathrm{Na}_{v} 1.3, \mathrm{Na}_{v} 1.6$ and $\mathrm{Na}_{v} 1.7$, respectively) but it didn't inhibit $\mathrm{Na}_{\vee} 1.4$ and $\mathrm{Na}_{\mathrm{V}} 1.5$, which are found primarily in muscle and heart, respectively at concentrations up to 3 $\mu \mathrm{M}$ (Fig. 1b, Table 1 in supplementary information).

\section{Design of the Fluorescence Peptide, Hs1a-FL}

We used recombinant Hs1a to synthesize Hs1a-FL, a NIR-labelled version of Hs1a (Fig 1c). We chose a NIR fluorophore for its emission wavelength with favorable tissue penetration potential for intraoperative applications. We modified Hs1a via nucleophilic substitution as previously described [26]. The synthesis was performed under basic conditions in a mixture of water and acetonitrile, with $14 \%$ yield. Retention time $\left(r_{t}\right)$ shifted from 12 min for the unmodified Hs1a to 16 min for Hs1a-FL (Fig. 2a and Fig. S1a). The major impurities were characterized as the partially reduced peptide, $3 \%\left(r_{t} 16.2 \mathrm{~min}\right)$, which was also present in the starting material $\left(r_{t} 12\right.$ min, 80\% and $r_{t} 12.2 \mathrm{~min}, 20 \%$ for Hs $1 a$ and reduced $\mathrm{Hs} 1 \mathrm{a}$, respectively). LC/MS spectra for both $\mathrm{Hs} 1 \mathrm{a}$ and $\mathrm{Hs} 1 \mathrm{a}-\mathrm{FL}$ showed clean peak families confirming the peptides' calculated masses of 3850.74 Da and 4482.12 Da for Hs1a and Hs1a-FL, respectively (Fig. 2b-C, Table 2 in supplementary material). In addition, florescence of $0.1 \mu \mathrm{M}$ Hs1a peptide and $0.1 \mu \mathrm{M} \mathrm{Hs} 1 \mathrm{a}-\mathrm{FL}$ were collected to confirm dye conjugation (Fig. 2d).

\section{Histology and Hs1a-FL imaging of mouse sciatic nerve}

To assess the possibility of using Hs1a-FL to image sciatic nerves in vivo, mice were injected intravenously with $\mathrm{Hs} 1 \mathrm{a}-\mathrm{FL}$ alone (4 nmol, $45 \mu \mathrm{M}$ of Hs1a-FL in $100 \mu \mathrm{L}$ of PBS) or in combination with an 
excess of unmodified peptide $(120 \mu \mathrm{M}, 12 \mathrm{nmol}$ in $100 \mu \mathrm{L}$ PBS, block), and sacrificed 30 min after injection. Nerves were surgically harvested and flash-frozen in OCT blocks. Blocks were then sliced on a cryotome at a $10 \mu \mathrm{m}$ thickness and imaged. Nerves were imaged to detect fluorescent signal and H\&E stained to enable the visualization of Schwann cells within the nerve structure. Anti- $\mathrm{Na}_{\mathrm{V}} 1.7$ immunohistochemistry confirmed target availability (Fig. 3a). Confocal microscopy confirmed the presence of Hs1a-FL signal in injected mice. No signal was detected in mice injected with PBS or "blocking solution" containing Hs1a-FL and a 3-fold molar excess of unlabeled Hs1a (Fig. 3b). In addition, no staining was observed when using isotype control antibodies, confirming specificity (Fig. S1b).

\section{Ex vivo Hs1a-FL biodistribution}

Mice were injected intravenously with Hs1a-FL alone (4 nmol, $45 \mu \mathrm{M}$ of Hs1a-FL in $100 \mu \mathrm{L}$ of PBS) or in combination with an excess of unmodified peptide (120 $\mu \mathrm{M}, 12 \mathrm{nmol}$ in $100 \mu \mathrm{L}$ PBS, blocking solution) and sacrificed 30 min after injection. The RSN and LSN were resected and epifluorescence imaging performed using an IVIS Spectrum imaging system (excitation $=710 / 45 \mathrm{~nm}$, emission $=800-820 \mathrm{~nm}$ ). In mice receiving just the imaging agent, we observed accumulation of $\mathrm{Hs} 1 \mathrm{a}-\mathrm{FL}$ in the resected sciatic nerves, which were clearly visible (Fig. 4a and Fig. S1C), whereas uptake was significantly reduced in the sciatic nerves of mice that received the imaging agent in combination with excess unmodified peptide, (radiant efficiency: $1.6 \pm 0.3 \times 10^{5}$ and $0.09 \pm 0.03 \times 10^{5}$ for $\mathrm{Hs} 1 \mathrm{a}-\mathrm{FL}$ and co-injection (blocking solution), respectively; Unpaired $t$-test, $p$-value $<0.001$, Fig. $4 \mathrm{~b}$ ). A trend towards higher fluorescence signals in the liver, kidney, brain and spleen was also observed (radiant efficiency: $3.0 \pm 2.0 \times 10^{7}$ and $0.002 \pm 0.001 \times$ $10^{7}, 1.4 \pm 1.1 \times 10^{7}$ and $0.005 \pm 0.004 \times 10^{7}, 0.2 \pm 0.1 \times 10^{7}$ and $0.001 \pm 0.0005 \times 10^{7}$ and $0.8 \pm 0.5 \times 10^{7}$ and $0.004 \pm 0.0003 \times 10^{7}$ for organs injected with fluorescent agent and with PBS, respectively; Fig. S2a and Fig. S2b).

\section{Discussion}

In the present study we developed and characterized Hs1a-FL, a near-infrared imaging agent to target human nerves. A limitation of the present study is that, in a small rodent model, the high liver accumulation makes it difficult to discern the signal coming from $\mathrm{Na}_{\mathrm{v}}$ 1.7-expressing nerve and unspecific liver signal. However, this limitation could be overcome in humans thanks to a more favorable anatomy and nerves with larger diameters. Hs1a is a peptide derived from the venom of a Chinese tarantula, with a low nanomolar affinity for neuronal sodium channels. Here, we showed that conjugation of Hs1a and Cy7.5 dye yields a fluorescent tracer for nerve imaging. The synthesis of Hs1a-FL was straightforward 
and efficient. We evaluated Hs1a-FL for ex vivo imaging of resected sciatic nerves via microscopy as well as imaging of exposed nerves via epifluorescence. The chosen mouse model for the in vivo investigation was athymic nude mice for their versatility and ease of use. Furthermore, nude mice do not have a furred skin and therefore allow an easier surgical exposure of the nerves without the need of hair removal. The mouse model should not affect the efficacy of Hs1a-FL in imaging nerves. Hs1a-FL was shown to specifically bind to $\mathrm{Na}_{\mathrm{v}} 1.7$ channels in vivo post intravenous injection and its binding could be blocked by competition with an excess dose of the unlabeled $\mathrm{Hs} 1 \mathrm{a}$. We speculate that the accumulation of the Hs1a-FL peptide in the spleen, kidney, liver and brain might be due to the fact that a presence of four lysines and one more terminal amine represent different potential attachment points for the fluorescent imaging agent. This is a clear challenge for future development which will require a more rigid control on the synthesis of this molecule. A more specific nerve agent could improve imaging potential and significantly limit background noise and possible toxicity. The near-infrared emission spectrum of Cy7.5 may enable the use this agent for visualization of nerves that are beneath the tissue surface during surgical interventions. In the preclinical settings, however, the high liver accumulation was a limitation to our ability to image the nerves in vivo without exposing the nerves; the liver signal was too strong to allow visualization of the rather small sciatic nerves. This issue could be bypassed by a superior imager and should not represent a limitation in humans. A broader investigation is needed to identify the most ideal nerve imaging agent for intraoperative applications. This study represents the scientific basis for the development of a set of nerve-targeting agents derived from naturally available peptides.

\section{Conclusion}

Hs1a-FL proved to be a useful tool for nerve visualization. This nerve-targeting agent should be explored further with a view to developing tools that can assist surgeons to identify peripheral nerves and avoid surgical morbidity due to nerve injury.

\section{Declarations}

Ethics approval (animal work): All applicable international, national, and/or institutional guidelines for the care and use of animals were followed.

Consent for publication: All of the authors have read and approved the manuscript and possible conflict of interests are disclosed.

Availability of data and material: All data and material are made available.

Competing of interest: T.R. is shareholder of Summit Biomedical Imaging, LLC and paid consultant for Theragnostics, Inc. J.G., P.D.d.S.F., G.F.K., J.S.L. and T.R. filed a patent surrounding the use of fluorophores with Hs1a and Hsp1a. 
Funding: This work was supported by the National Institutes of Health (grants R01 CA204441, P30 CA008748, R35 CA232130), the Australian National Health and Medical Research Council (Program Grant APP1072113 and Principal Research Fellowship APP1136889 to G.F.K.), and University of Queensland International Postgraduate Research Scholarships to J.K.K and C.Y.C. The authors thank the Tow Foundation and Memorial Sloan Kettering Cancer Center's Center for Molecular Imaging \& Nanotechnology (CMINT), the Imaging and Radiation Sciences Program, MSK Experimental Therapeutics Center, and the MSK Molecularly Targeted Intraoperative Imaging Fund. L.M.C acknowledges support from the Ruth L. Kirschstein fellowship (NIH F32 EB025050). The funding sources were not involved in study design, data collection and analysis, writing of the report, or the decision to submit this article for publication.

Authors' contributions: JG and GP contributed equally to the design and performing of experiments, obtaining and interpreting data, and to the writing of the manuscript. CY, PDdSF, LMC, JKK, and NG, contributed to performing experiments, obtaining and interpreting data, and revising the manuscript. JSL, GFK and TR designed the experiments, contributed to the interpretation of data and supervised the project.

\section{References}

1.

Grinsell D, Keating CP. Peripheral nerve reconstruction after injury: a review of clinical and experimental therapies. Biomed Res Int. 2014;2014:698256.

2 .

Campbell WW. Evaluation and management of peripheral nerve injury. Clin Neurophysiol. 2008;119:1951-65.

3.

Antoniadis G, Kretschmer T, Pedro MT, König RW, Heinen CPG. Richter H-P latrogenic nerve injuries: prevalence, diagnosis and treatment. Dtsch Arztebl Int. 2014;111:273-9.

4.

Kretschmer T, Heinen CW, Antoniadis G, Richter HP. König RW latrogenic nerve injuries. Neurosurg Clin N Am. 2009;20:73-90.

5 .

Gordin E, Lee TS, Ducic Y, Arnaoutakis D. Facial nerve trauma: evaluation and considerations in management. Craniomaxillofac Trauma Reconstr. 2015;8:1-13.

6.

Varaldo E, Ansaldo GL, Mascherini M, Cafiero F, Minuto MN. Neurological complications in thyroid surgery: a surgical point of view on laryngeal nerves. Front Endocrinol (Lausanne). 2014;5:108. 
7.

Echternach M, Maurer CA, Maurer C, Mencke T, Schilling M, Verse T, et al. Laryngeal complications after thyroidectomy: is it always the surgeon. Arch Surg. 2009;144:149-53.

8.

Sosa JA, Bowman HM, Tielsch JM, Powe NR, Gordon TA. Udelsman R The importance of surgeon experience for clinical and economic outcomes from thyroidectomy. Ann Surg. 1998;228:320-30.

9.

Crombie IK, Davies HT, Macrae WA. Cut and thrust: antecedent surgery and trauma among patients attending a chronic pain clinic. Pain. 1998;76:167-71.

10.

Tasmuth T, von Smitten K, Hietanen P, Kataja M, Kalso E. Pain and other symptoms after different treatment modalities of breast cancer. Ann Oncol. 1995;6:453-9.

11.

Schneider B, Schickinger-Fischer B, Zumtobel M, Mancusi G, Bigenzahn W, Klepetko W, et al. Concept for diagnosis and therapy of unilateral recurrent laryngeal nerve paralysis following thoracic surgery. Thorac Cardiovasc Surg. 2003;51:327-31.

12.

Sihag S, Wright CD. Prevention and management of complications following tracheal resection. Thorac Surg Clin. 2015;25:499-508.

13.

Yumoto E, Sanuki T, Kumai Y. Immediate recurrent laryngeal nerve reconstruction and vocal outcome. Laryngoscope. 2006;116:1657-61.

14.

Li H, Hu Y, Huang J, Yang Y, Xing K. Luo Q Attempt of peripheral nerve reconstruction during lung cancer surgery. Thorac Cancer. 2018;9:580-3.

15.

Barnoiu OS, Garcia Galisteo E, Baron Lopez F, Vozmediano Chicharro R, Soler Martinez J, Del Rosal Samaniego JM, et al. Prospective urodynamic model for prediction of urinary incontinence after robotassisted radical prostatectomy. Urol Int. 2014;92:306-9.

16.

Walsh PC. Donker PJ Impotence following radical prostatectomy: insight into etiology and prevention. J Urol. 2017;197:165-70.

17.

Walz J, Burnett AL, Costello AJ, Eastham JA, Graefen M, Guillonneau B, et al. A critical analysis of the current knowledge of surgical anatomy related to optimization of cancer control and preservation of continence and erection in candidates for radical prostatectomy. Eur Urol. 2010;57:179-92.

18.

Cage TA, Yuh EL, Hou SW, Birk H, Simon NG, Noss R, et al. Visualization of nerve fibers and their relationship to peripheral nerve tumors by diffusion tensor imaging. Neurosurg Focus. 2015;39:E16. 19. 
Skorpil M, Karlsson M, Nordell A. Peripheral nerve diffusion tensor imaging. Magn Reson Imaging. 2004;22:743-5.

20.

Strakowski JA, Ultrasound-Guided Peripheral Nerve Procedures. Phys Med Rehabil Clin N Am. 2016;27:687-715.

21.

Hussain T, Nguyen LT, Whitney M, Hasselmann J. Nguyen QT Improved facial nerve identification during parotidectomy with fluorescently labeled peptide. Laryngoscope. 2016;126:2711-7.

22.

Carolus AE, Lenz M, Hofmann M, Welp H, Schmieder K, Brenke C. High-resolution in vivo imaging of peripheral nerves using optical coherence tomography: a feasibility study. J Neurosurg. 20191-7. 23.

Walsh EM, Cole D, Tipirneni KE, Bland KI, Udayakumar N, Kasten BB, et al. Fluorescence imaging of nerves during surgery. Ann Surg. 2019;270:69-76.

24.

Hingorani DV, Whitney MA, Friedman B, Kwon JK, Crisp JL, Xiong Q, et al. Nerve-targeted probes for fluorescence-guided intraoperative imaging. Theranostics. 2018;8:4226-37.

25.

Cha J, Broch A, Mudge S, Kim K, Namgoong JM, Oh E, et al. Real-time, label-free, intraoperative visualization of peripheral nerves and micro-vasculatures using multimodal optical imaging techniques. Biomed Opt Express. 2018;9:1097-110.

26.

Gonzales J, Demetrio de Souza Franca P, Jiang Y, Pirovano G, Kossatz S, Guru N, et al. Fluorescence imaging of peripheral nerves by a Nav1.7-targeted inhibitor cystine knot peptide. Bioconjugate Chem. 2019.

27.

Whitney MA, Crisp JL, Nguyen LT, Friedman B, Gross LA, Steinbach P, et al. Fluorescent peptides highlight peripheral nerves during surgery in mice. Nat Biotechnol. 2011;29:352-6.

28.

Langhout GC, Kuhlmann KFD, Wouters MWJM, van der Hage JA, van Coevorden F, Müller M, et al. Nerve detection during surgery: optical spectroscopy for peripheral nerve localization. Lasers Med Sci. 2018;33:619-25.

29.

He K, Zhou J, Yang F, Chi C, Li H, Mao Y, et al. Near-infrared Intraoperative Imaging of Thoracic Sympathetic Nerves: From Preclinical Study to Clinical Trial. Theranostics. 2018;8:304-13. 30.

Langhout GC, Bydlon TM, van der Voort M, Müller M, Kortsmit J, Lucassen G, et al. Nerve detection using optical spectroscopy, an evaluation in four different models: In human and swine, in-vivo, and post mortem. Lasers Surg Med. 2018;50:253-61.

31. 
Shin JG, Hwang HS, Eom TJ, Lee BH. In vivo three-dimensional imaging of human corneal nerves using Fourier-domain optical coherence tomography. J Biomed Opt. 2017;22:10501.

32.

King GF, Vetter I. No gain, no pain: NaV1.7 as an analgesic target. ACS Chem Neurosci. 2014;5:749-51. 33.

Klint JK, Senff S, Saez NJ, Seshadri R, Lau HY, Bende NS, et al. Production of recombinant disulfide-rich venom peptides for structural and functional analysis via expression in the periplasm of E. coli. PLoS One. 2013;8:e63865.

\section{Figures}
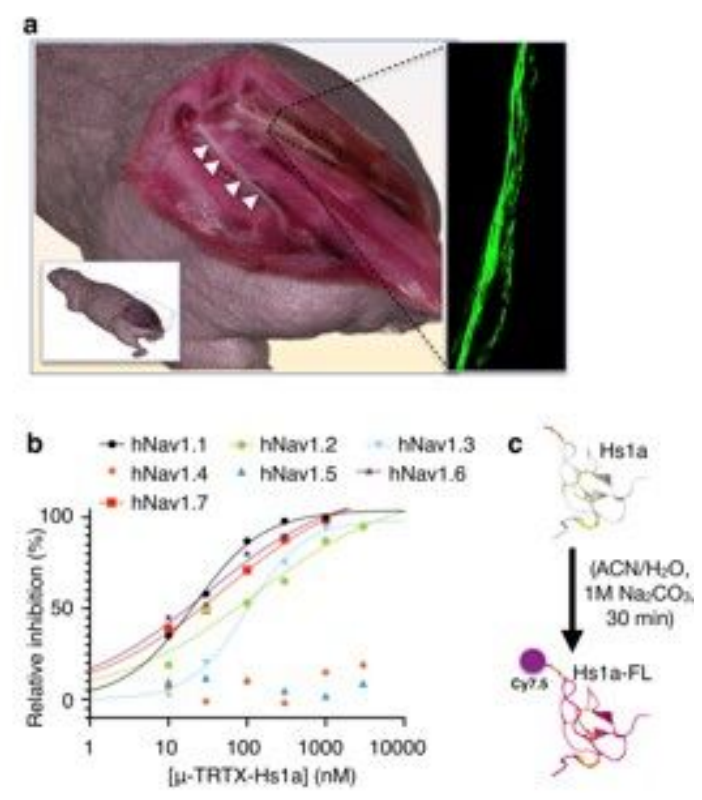

\section{Figure 1}

Ion channel selectivity and chemical synthesis of Hs1a-FL. (a) Representative view of the experimental settings. A 3D rendering of a frozen and sliced mouse. White arrows show the left sciatic nerve. Right sciatic nerve magnification shows the fluorescent $\mathrm{Hs} 1 \mathrm{a}-\mathrm{FL}$ agent bound to the nerve surface. (b) Selectivity of Hs1a towards human NaV channels stably expressed in HEK293 cells. Calculated IC50 values were: hNaV1.1; 19.4 nM, hNaV1.2; 81.2 nM, hNaV1.3; 106.8 nM, hNaV1.4; >3000nM, hNaV1.5; $>3000 \mathrm{nM}, \mathrm{hNaV1}$.6; $19.2 \mathrm{nM}, \mathrm{hNaV1.7;} 26.9 \mathrm{nM}$. Each point on the curve is an average of 3-11 cells. (c) Reaction scheme for conjugation of Hs1a peptide with Cyanine7.5-NHS ester dye. The ribbon model of Hs1a-FL shows disulfide bridges (in yellow) and shows attachment of one dye to the peptide (orange/blue). 

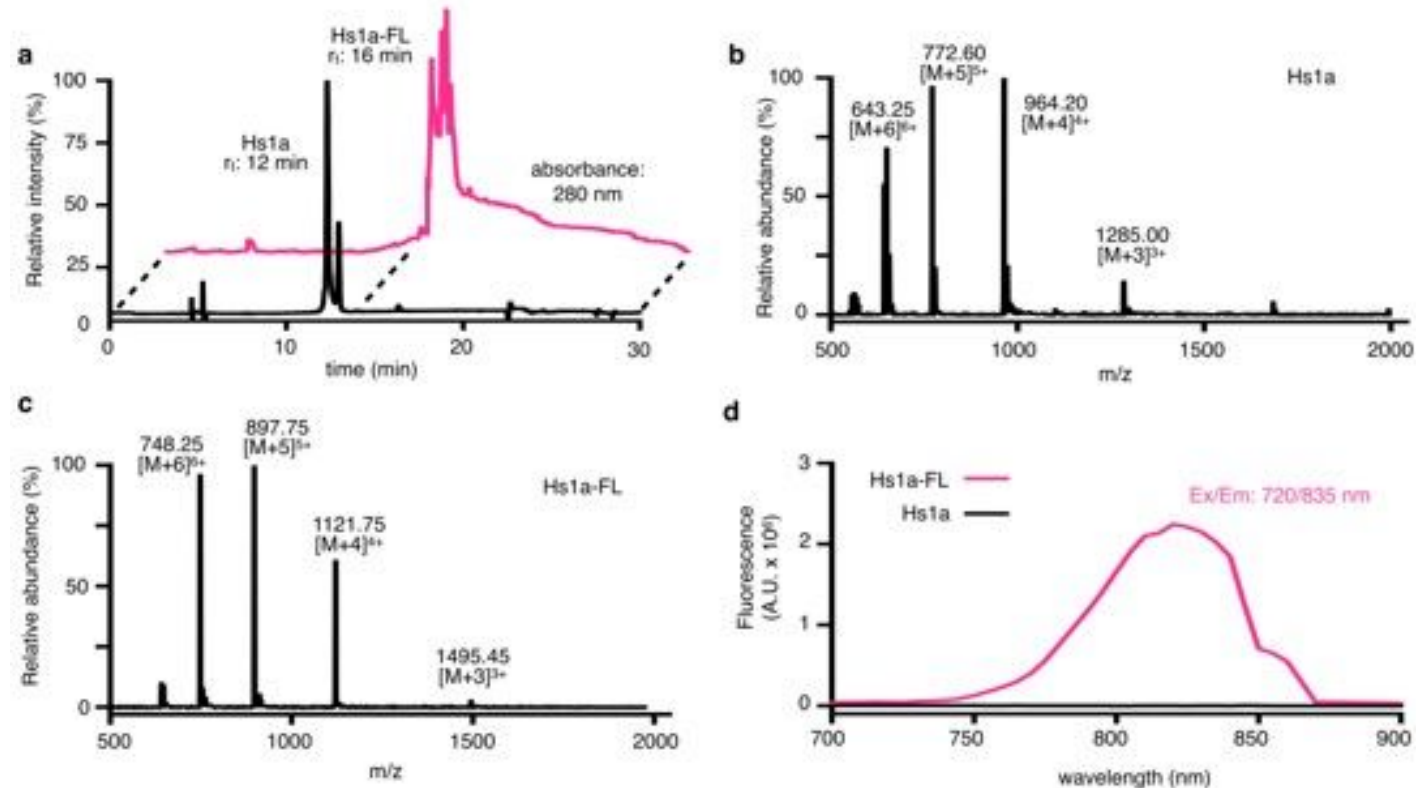

d

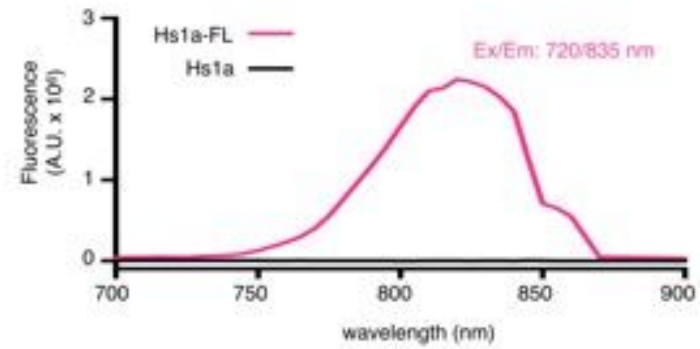

Figure 2

Chemical characterization of Hs1a-FL. (a) RP-HPLC chromatograms of Hs1a (black) and Hs1a-FL (pink) with absorbances observed at $280 \mathrm{~nm}$. (b) LC-MS spectrum of Hs1a and (c) of Hs1a-FL. The mass spectra show four major ion species that correspond to the calculated mass of Hs1a peptide and four major ion species that confirm the calculated mass of Hs1a-FL after dye conjugation. (d) Fluorescence spectra (Ex/Em: 720/835 nm) of $0.1 \mu \mathrm{M} \mathrm{Hs1a} \mathrm{peptide} \mathrm{(black)} \mathrm{and} 0.1 \mu \mathrm{M}$ Hs1a-FL (pink)

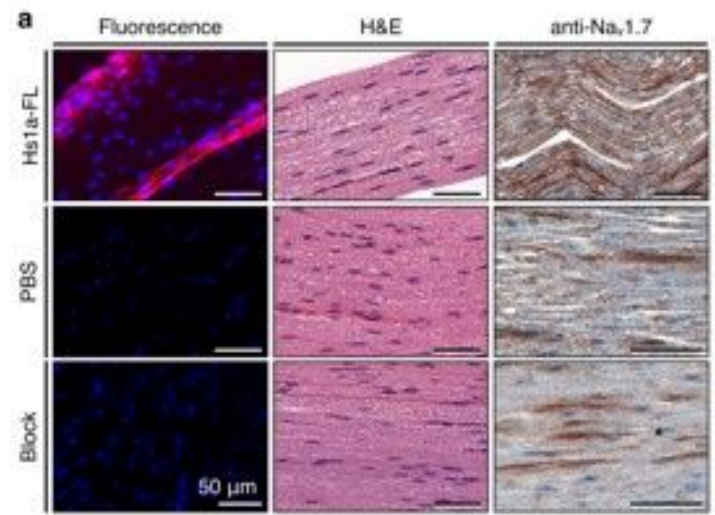

b

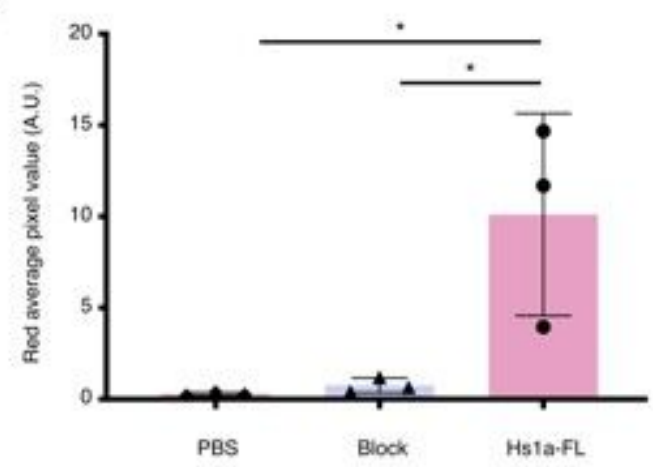

Figure 3 
Ex vivo microscopy imaging of Hs1a-FL in mouse sciatic nerve. (a) Fluorescence of Hs1a-FL stained mouse sciatic nerves compared to mice injected with vehicle (PBS) or co-injected with Hs1a (Hs1a-FL, 45 $\mu \mathrm{M}, 4 \mathrm{nmol}$ and Hs1a $120 \mu \mathrm{M}, 12 \mathrm{nmol}$ in $100 \mu \mathrm{L}$ PBS). H\&E staining of adjacent nerve tissue and IHC staining, confirming expression of NaV1.7. (b) Quantification of total detected fluorescence. Unpaired ttest. * $p$-value $<0.05$.
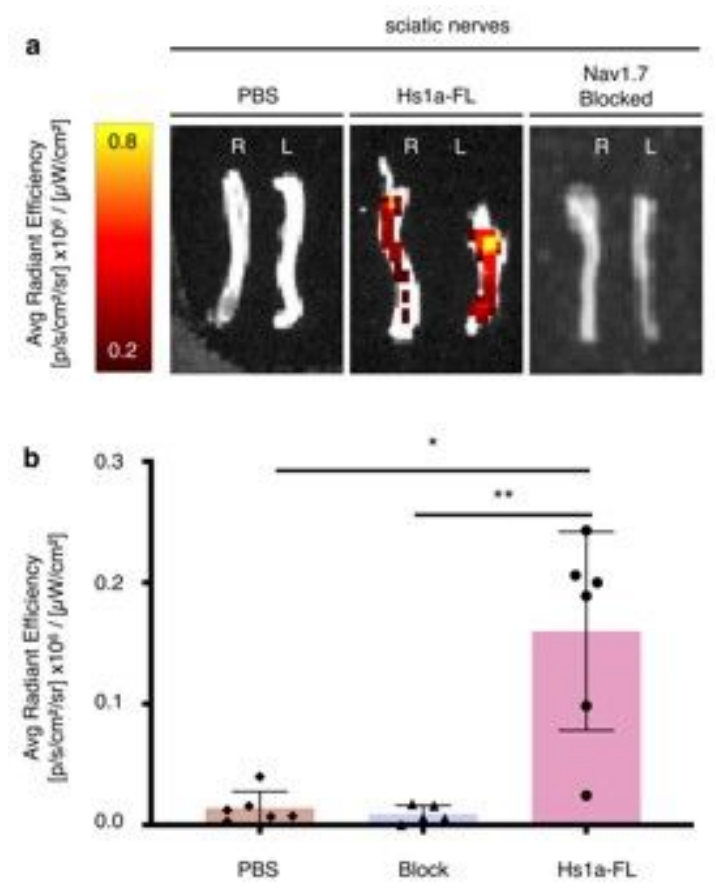

\section{Figure 4}

Epifluorescence imaging of fresh, unprocessed mouse sciatic nerves with Hs1a-FL. (a) Epifluorescence images of resected sciatic nerves from animals injected with PBS, Hs1a-FL (4 nmol, $45 \mu \mathrm{M}$ of Hs1a-FL in $100 \mu \mathrm{L}$ of PBS), a Hs1a/Hs1a-FL mixture (Hs1a-FL, $45 \mu \mathrm{M}, 4 \mathrm{nmol}$ and Hs1a $120 \mu \mathrm{M}, 12 \mathrm{nmol}$ in $100 \mu \mathrm{L}$ PBS). Images were taken $30 \mathrm{~min}$ after tail vein injection. (b) Fluorescence intensity quantification. Unpaired t-test. ${ }^{*}$-value $<0.05 ;{ }^{* \star}$ p-value $<0.01$.

\section{Supplementary Files}

This is a list of supplementary files associated with this preprint. Click to download.

- Hs1apaperJGSupplementary5.docx 